\title{
UMA ANÁLISE DA PROTEÇÃO DE DADOS EM TEMPOS DE PANDEMIA A PARTIR DA MP 954/2020
}

\author{
AN ANALYSIS OF DATA PROTECTION IN PANDEMIC TIMES \\ FROM MP 954/2020
}

Lucimara Plaza Tena ${ }^{1}$

Dirceu Pereira Siqueira ${ }^{1}$

Recebido em: 29/05/2020 Aceito em: 10/11/2021

luciplaza@hotmail.com dpsiqueira@uol.com.br

\begin{abstract}
Resumo: $O$ artigo tem por objetivo analisar a privacidade de dados pessoais em contextos excepcionais, como o da pandemia COVID-19, momentos em que os riscos à vida humana são intensificados. Situações de anormalidade geram dificuldades aos poderes do Estado que precisam decidir. Nesse sentido, o estudo se propõe a analisar a MP 954/2020, que requer o compartilhamento de dados das teles com o poder público, para identificar, a partir de hipóteses visualizadas, qual o limite aceitável da presença do Estado na privacidade do indivíduo, sem que para isso viole direitos fundamentais e da personalidade. A conclusão vislumbrada para o problema identificado é que será necessário um equilíbrio que deverá ser encontrado a partir de instrumentos de controle social. O método utilizado é o hipotético dedutivo e a metodologia empregada é a revisão bibliográfica.
\end{abstract}

Palavras-chave: COVID-19. Direitos da personalidade e fundamentais. MP 954/2020. Políticas Públicas. Privacidade de dados pessoais.

\begin{abstract}
The article aims to analyze the privacy of personal data in exceptional contexts, such as the pandemic COVID-19, times when the risks to human life are intensified. Situations of abnormality generated with difficulties in the powers of the State that require decisions. In this sense, the study can analyze MP 954/2020, which requires the sharing of telephone data with the public authorities, to identify, based on visualized hypotheses, what is the acceptable limit of the State's presence in the privacy of the individual, without that for this violates fundamental and personality rights. A foreseen conclusion for the identified problem is that a balance will be needed that must be found from instruments of social control. The method used is the hypothetical deductive and the methodology used is a bibliographic review.
\end{abstract}

Keywords: COVID-19. MP 954/2020. Personality and fundamental rights. Privacy of personal data. Public policy.

\section{INTRODUÇÃO}

O presente artigo tem por objetivo analisar a privacidade de dados pessoais em contexto social de epidemia, pandemia, calamidade pública ou circunstâncias de grave risco à população que exigem ações imediatas do poder público em prol da vida humana. Situações de anormalidade geram dificuldades aos poderes do Estado e consequências severas em termos econômicos, saúde ou segurança pública, por exemplo, e acabam por atingir os direitos da personalidade e fundamentais dos indivíduos.

O estudo se utiliza como pano de fundo da MP 954/2020 (BRASIL.e, 2020) publicada em 17 abril de 2020, e das discussões presentes na ADI 6387 (BRASIL.i, 2020), proposta pelo Conselho Federal da Ordem dos Advogados do Brasil (CFOAB), bem como das demais ações direta de

\footnotetext{
${ }^{1}$ Centro Universitário de Maringá - Unicesumar - Paraná - Brasil
} 
inconstitucionalidade $^{2}$, todas geradas em razão da referida norma que determinou o compartilhamento de dados por empresas de telecomunicações prestadoras de Serviço Telefônico Fixo Comutado e de Serviço Móvel Pessoal com a Fundação Instituto Brasileiro de Geografia e Estatística (IBGE), a fim de que se produza estatística mediante entrevistas não presenciais.

A Lei Geral de Proteção de Dados Pessoais (LGPD), que acredita-se entrar em vigor em 03 de maio de $2021^{3}$, tem por fim proteger os dados pessoais dos indivíduos. Contudo, apesar da orientação nela prevista, o governo federal solicitou genericamente, por meio da MP dados pessoais inseridos nos cadastros da teles com o objetivo de utilizá-los em pesquisas relacionadas ao COVID19. Bem, como as justificativas não convenceram, diversas ADI foram protocoladas junto ao Supremo Tribunal Federal (STF), discutindo a ilegalidade da Medida. Sabe-se que haverá um longo caminho até que uma decisão da Suprema Corte pacifique a questão. A despeito do momento delicadíssimo que o Brasil se encontra, assim como os demais países, a discussão da medida é oportuna, pois urge que se estabeleça limites claros para o compartilhamento de dados pessoais com o poder público em períodos de normalidade ou não.

Assim, o problema que se discute é qual o limite permitido ao Estado para que obtenha acesso aos dados pessoais dos indivíduos sem que o faça ilegalmente e ilegitimamente. Para tanto, algumas hipóteses são alçadas e discutidas a fim de que se encontre um parâmetro razoável de compartilhamento em momentos de crise, como atual, de pandemia em decorrência da COVID-19.

O artigo se divide basicamente em: considerações gerais sobre a doença COVID-19, razões da MP 954/2020 no contexto da epidemia, privacidade de dados; aspectos jurídicos da ADI e limites visualizados; da ideia da solidariedade que justificaria o compartilhamento e direitos da personalidade que deverão ser analisados pelo viés da pandemia, para enfim concluir que há um limite tênue entre o permitido e o proibido, inclusive para o Estado.

O método utilizado é o hipotético dedutivo e a metodologia se valeu da revisão bibliográfica, legislação, jurisprudência e decisões em curso em razão da ADI 6387. O referencial teórico se sustenta em Alain Supiot.

\section{COMO A COVID-19 SURGIU E SE ESPALHOU}

De acordo com informações contidas na página da Organização Pan-Americana da Saúde/Organização Mundial da Saúde (OMS) - Brasil, a OMS foi alertada em 31 de dezembro de 2019, sobre a existência de casos de pneumonia que surgiram na cidade de Wuhan, província de

\footnotetext{
${ }^{2}$ Até a data do dia 23/05/2020, além do CFOAB, outras ações de ADI também foram propostas pelo Partido da Social Democracia Brasileira - PSDB (ADI 6388), pelo Partido Socialista Brasileiro - PSB (ADI 6389), pelo Partido Socialismo e Liberdade - PSOL (ADI 6390) e pelo Partido Comunista do Brasil (ADI 6393). Até a data do dia 23/05/2020.

3 Há uma instabilidade quanto a data efetiva que a LGPD entrará em vigor. Em 29/04/2020, entrou em vigor a MP 959/2020, a qual trata do pagamento do Benefício Emergencial, mas que no art. $4^{\circ}$ altera a vigência da Lei para 03 de maio de 2021. BRASIL. MEDIDA PROVISÓRIA № 959, de 29 de abril de 2020. Estabelece a operacionalização do pagamento do Benefício Emergencial de Preservação do Emprego e da Renda e do benefício emergencial mensal de que trata a Medida Provisória no 936, de 1ำ de abril de 2020, e prorroga a vacatio legis da Lei oํ 13.709, de 14 de agosto de 2018, que estabelece a Lei Geral de Proteção de Dados Pessoais - LGPD. Disponível em: http://www.planalto.gov.br/ccivil 03/ ato2019-2022/2020/Mpv/mpv959.htm. Acesso em: 23 maio 2020.
} 
Hubei, na República Popular da China. Tratava-se de uma nova cepa (tipo) de coronavírus que não havia sido identificada antes em seres humanos", contudo, a confirmação efetiva pelas autoridades chinesas ocorreu apenas em 7 de janeiro de 2020. (OPAS/OMS Brasil, 2020).

A OPAS/OMS Brasil informa que já foram identificados sete coronavírus humanos (HCoVs): "HCoV-229E, HCoV-OC43, HCoV-NL63, HCoV-HKU1, SARS-COV (que causa síndrome respiratória aguda grave), MERS-COV (que causa síndrome respiratória do Oriente Médio) e o, mais recente, novo coronavírus (que no início foi temporariamente nomeado 2019-nCoV." Apenas em 11 de fevereiro de 2020 recebeu o nome de SARS-CoV-2. "Esse novo coronavírus é o responsável por causar a doença COVID-19." (OPAS/OMS Brasil, 2020).

Com o objetivo de "aprimorar a coordenação, cooperação e a solidariedade global para interromper a propagação do vírus", em 30 de janeiro de 2020, a OMS, diante do evidente risco às vidas humanas espalhadas pelo globo, declara "que o surto do novo coronavírus constitui uma Emergência de Saúde Pública de Importância Internacional (ESPII) - o mais alto nível de alerta da Organização, conforme previsto no Regulamento Sanitário Internacional." (OPAS/OMS Brasil, 2020).

Esta é a sexta vez que a ESPII é declarada na história, vale dizer, o mundo já esteve em risco em ocasiões anteriores, como em " 25 de abril de 2009 - pandemia de H1N1; 5 de maio de 2014 disseminação internacional de poliovírus; 8 de agosto de 2014 - surto de Ebola na África Ocidental; 1 de fevereiro de 2016 - vírus zika e aumento de casos de microcefalia e outras malformações congênitas; 18 maio de 2018 - surto de ebola na República Democrática do Congo." (OPAS/OMS Brasil, 2020).

Em 11 de março de 2020 a OMS caracterizou a COVID-19 como uma pandemia ${ }^{4}$ (OPAS/OMS Brasil, 2020). A partir desta data, diversos prefeitos e governadores que já tinham iniciado trabalhos de prevenção à proliferação da doença, tornaram as medidas ainda mais restritivas no Brasil, sugerindo em um primeiro momento, para em seguida tornar obrigatório $\mathrm{o}$ isolamento social, com o objetivo de conter a proliferação da doença. Em algumas cidades foi preciso adotar o "lockdown", como em São Luiz (MA) (REUTERS; 2020), primeira cidade a se valer da medida no país (05/05/2020) e Prefeitura de Campina Grande do Sul ${ }^{5}$ (13/05/2020), que determinou restrição em três localidades da área rural do município (RPC Curitiba, 2020). Infelizmente São Luiz e Campina Grande do Sul não são as únicas que optaram pelo Lockdown.

O novo Coronavírus é o responsável pela doença infecciosa conhecida mundialmente por COVID-19, cujos sintomas "são febre, cansaço e tosse seca. Alguns pacientes podem ter dores, congestão nasal, corrimento nasal, dor de garganta ou diarreia." (OPAS BRASIL, 2020). O Ministério da Saúde (MS) informa que o quadro clínico varia de infecções assintomáticas a quadros respiratórios graves. A Organização Mundial de Saúde (OMS) esclarece que $80 \%$ dos pacientes podem ser assintomáticos, $20 \%$ podem exigir atendimento hospitalar por conta de dificuldades respiratórias e $5 \%$ aproximadamente desses casos podem necessitar de suporte para o tratamento de insuficiência respiratória (suporte ventilatório). (BRASIL, 2020).

\footnotetext{
4 "O termo "pandemia" se refere à distribuição geográfica de uma doença e não à sua gravidade. A designação reconhece que, no momento, existem surtos de COVID-19 em vários países e regiões do mundo." (OPAS/OMS Brasil, 2020).

${ }^{5}$ Localizada na Região Metropolitana de Curitiba (PR)
} 
Informações como a forma de comportamento do vírus em cada país onde está acontecendo a contaminação dependerá de dados estatísticos e da qualidade dos controles efetuados pelos governantes nas diversas esferas. Em um contexto de pandemia (abril de 2020), em um cenário de escassos recursos financeiros para controles efetivos, talvez as informações disponíveis não sejam as mais exatas, complicando ainda mais a necessidade de decisões pelos Estados em prol de seus governados.

A forma de contágio da doença é muito rápida e acontece, segundo o Ministério da Saúde (MS) "de uma pessoa doente para outra ou por contato próximo por meio de toque do aperto de mão; gotículas de saliva; espirro; tosse; catarro; objetos ou superfícies contaminadas, como celulares, mesas, maçanetas, brinquedos, teclados de computador etc." (BRASIL.j, 2020). Diante da facilidade de contaminação, atualmente em diversas cidades no Brasil, os moradores devem se utilizar de máscaras quando estiverem em público. $\mathrm{O}$ objetivo é que tal conduta funcione como uma barreira mecânica evitando principalmente que pessoas assintomáticas transmitam a doença.

O MS recomenda algumas medidas de prevenção à COVID-19, são elas:

- Lave com frequência as mãos até a altura dos punhos, com água e sabão, ou então higienize com álcool em gel 70\%.

- Ao tossir ou espirrar, cubra nariz e boca com lenço ou com o braço, e não com as mãos.

- Evite tocar olhos, nariz e boca com as mãos não lavadas.

- Ao tocar, lave sempre as mãos como já indicado.

- Mantenha uma distância mínima de cerca de 2 metros de qualquer pessoa tossindo ou espirrando.

- Evite abraços, beijos e apertos de mãos. Adote um comportamento amigável sem contato físico, mas sempre com um sorriso no rosto.

- Higienize com frequência o celular e os brinquedos das crianças.

- Não compartilhe objetos de uso pessoal, como talheres, toalhas, pratos e copos.

- Mantenha os ambientes limpos e bem ventilados.

- Evite circulação desnecessária nas ruas, estádios, teatros, shoppings, shows, cinemas e igrejas. Se puder, fique em casa.

- Se estiver doente, evite contato físico com outras pessoas, principalmente idosos e doentes crônicos, e fique em casa até melhorar.

- Durma bem e tenha uma alimentação saudável.

- Utilize máscaras caseiras ou artesanais feitas de tecido em situações de saída de sua residência.

As mencionadas medidas nem sempre são fáceis de execução, principalmente no Brasil cujas dimensões são gigantescas. Veja que em algumas regiões do país há falta de estruturas sanitárias mínimas como água e esgoto; pessoas moram em favelas com número excessivo de indivíduos por $\mathrm{m}^{2}$; o desemprego cresce, e há aqueles que não dispõem de recursos financeiros nem mesmo para a compra de comida, o que pensar então para os produtos de higiene, como o álcool em gel $70 \%$ para higienização das mãos. Alguns dos exemplos mencionados se caracterizam como situações de vulnerabilidades e que juntas se potencializam e elevam o risco social para a manutenção da vida.

Vulnerabilidades como aquelas ligadas a aspectos econômicos, sociais ou a saúde, sempre existiram e já deveriam ter recebido o tratamento adequado, como isso não ocorreu, a presença da 
COVID-19 agravou aquilo que já era péssimo. Os problemas varridos para debaixo dos tapetes não poderiam ali permanecer por muito tempo, e infelizmente a pandemia é mais um a ser enfrentado.

\section{DA MP 954/2020 NO CONTEXTO COVID-19}

A Medida Provisória 954/2020, publicada no Diário Oficial da União em 17/04/2020, na edição 74-C, Seção: 1 - Extra, Página: 1, cuja EMENTA

Dispõe sobre o compartilhamento de dados por empresas de telecomunicações prestadoras de Serviço Telefônico Fixo Comutado e de Serviço Móvel Pessoal com a Fundação Instituto Brasileiro de Geografia e Estatística, para fins de suporte à produção estatística oficial durante a situação de emergência de saúde pública de importância internacional decorrente do coronavírus (covid-19), de que trata a Lei no 13.979, de 6 de fevereiro de 2020. (BRASIL.e, 2020).

Diante da ação do chefe do Executivo, no dia 20 de abril de 2020, o Conselho Federal da Ordem dos Advogados do Brasil - CFOAB, ajuizou junto ao Supremo Tribunal Federal (STF), Ação Direta de Inconstitucionalidade com Pedido Cautelar

em face da integralidade dos dispositivos estabelecidos pela Medida Provisória n. 954, de 17 de abril de 2020, por violação direta aos artigos $1^{\circ}$, inciso III e 50, incisos X e XII da Constituição Federal, os quais asseguram, respectivamente a dignidade da pessoa humana; a inviolabilidade da intimidade, da vida privada, da honra e da imagem das pessoas; o sigilo dos dados e a autodeterminação informativa.

A ADI 6387 (BRASIL.i, 2020) proposta rebate a MP 954/2020 em todos os seus pontos e indica preocupação com a vulnerabilidade a qual o cidadão brasileiro poderá estar exposto. Apesar de reconhecer os fortes argumentos trazidos pela ação, o presente estudo não tem por objeto o posicionamento político em relação a MP ou a ADI proposta, mas apenas dentro de um pensamento científico refletir sobre os direitos fundamentais e da personalidade que envolvem a privacidade, intimidade e sigilo de dados dentro do contexto da pandemia da COVID-19 que se instalou no Brasil.

Assim, o que se quer é lançar luzes na discussão que ocupa o cenário jurídico em 2020 em meio a uma realidade inóspita e desconhecida que exige ajustes dos Poderes da República, em prol de um bem maior, qual seja, a vida de milhares de brasileiros. É certo que as decisões assumidas pelos governantes em qualquer das esferas possivelmente não serão avaliadas pela história como as melhores. Mas depois que o caminho foi literalmente aberto e percorrido com os artefatos que se dispunha para aquele momento, e isso inclui não apenas capacidade intelectual, mas recursos de informações e tempo disponível para agir, as avaliações se tornarão mais confortáveis para o expectador.

Então, ainda que as luzes do presente artigo ou da ADI proposta, não sejam as melhores, sem dúvida, contribuirá para que a estrada seja construída em um mundo que o perigo embora invisível, tem a capacidade de exterminar vidas em dias e destruir ou abalar a economia de países, a 
exemplo do que já aconteceu com a Itália, Espanha, França, EUA, além do próprio Brasil. O que fazer? Aprender com os erros e acertos dos vizinhos e seguir em frente tentando escolher o melhor. Isto posto, analisar-se os principais pontos da MP que envolvem a privacidade do indivíduo.

\section{DO VALOR DOS SIGNOS LIBERDADE E DA PRIVACIDADE}

Supiot comenta que a vida do indivíduo não se desenvolve apenas "no universo das coisas, mas também num universo de signos." (SUPIOT, 2007, p. VII, Prólogo). A privacidade pode ser considerada um desses signos caros e que de valor inestimável, remete a um outro, a liberdade, a qual materializa todas as conquistas da humanidade ao longo da história. É por ela que povos lutaram e, o perfume da sua presença mantem corações e mentes alertas diante de ações que possam colocá-la em risco. O estágio atual da humanidade não é o ideal e há muito o que se fazer em termos de privacidade ou liberdade, mas, o que já se conquistou não se pode perder.

Antes da pandemia, a leitura que se fazia do valor proteção dos dados pessoais era de um signo precioso, ligado a faculdade de autodeterminação do indivíduo e, portando, merecedor de proteção. São exemplos normas como a LGPD, Marco Civil da Internet (Lei n. 12.965/2014) e da própria Constituição Federal (BRASIL.a, 1988) que buscam manter a salvo a privacidade, como direito da personalidade e fundamental. Dessa forma, a publicação da MP 954/2020 foi observada com preocupação, uma vez que o seu conteúdo requer que empresas de telecomunicações compartilhem dados de seus consumidores, pessoas físicas ou jurídicas (BRASIL, 2020.e, art. $2^{\circ}$ ).

Sim, é indiscutível o valor da privacidade e o CFOAB tem razão em questionar na ADI proposta os termos da MP 954/2020, expressando preocupações em relação à democracia nacional e aos riscos aos direitos fundamentais e da personalidade. Em um momento de crise todos os órgãos de controle devem estar atentos aos abusos cometidos em nome da proteção à vida. Então, obviamente que é legítima a ADI.

Por outro lado, se deve oferecer o benefício da dúvida as intenções da MP 954/2020 e com cientificidade analisar os fatos em um contexto de pandemia, anormalidade, riscos evidentes à vida humana e necessidade de ação rápida e eficiente para o momento. Na verdade, se conhece ainda pouco da doença e é necessário que decisões sejam tomadas ao longo do caminho. Não há um mapa ou um plano estratégico que se possa garantir sucesso absoluto, se faz o que é possível para aquele momento e o futuro mostra em seguida que nem sempre a escolha foi a correta.

A MP 954/2020 informa que os dados pessoais a serem compartilhados com o IBGE serão utilizados para a elaboração de "pesquisas para produção estatística oficial, com o objetivo de realizar entrevistas em caráter não presencial no âmbito de pesquisas domiciliares." (BRASIL.e, 2020, art. 2º, $\left.\S 1^{\circ}\right)$.

É preciso buscar o equilíbrio e para os juristas isso se expressa a partir de uma interpretação hermenêutica das normas que envolvem o fato, bem como da observação de princípios como da razoabilidade, proporcionalidade, legalidade e dignidade da pessoa humana. Mas, se é verdade que a ciência do Direito não pode estar imune a realidade da vida cotidiana, então, é interessante observar as preocupações que rondam o universo fora da academia.

Revista do Direito [ISSN 1982-9957]. Santa Cruz do Sul, n. 64, p. 91-111, maio-ago. 2021. https://online.unisc.br/seer/index.php/direito/index 
A CNN Brasil em programa dedicado a pandemia entrevistou o historiador Leandro Karnal. Na ocasião a jornalista Thais Herédia o questionou sobre o papel do Estado em tempos de COVID19, revelando preocupação com a delimitação de fronteira para o presente momento em que a população permite demais por que necessita muito do Estado. Inquiriu sobre como será "esse equilíbrio: permitir demais porque vamos precisar ser monitorados o tempo inteiro, necessitar demais porque é o único ente capaz de prover infinitamente [...]. Como é o equilíbrio entre a permissividade ao Estado e a necessidade dele?".

É justamente nesse contexto que a MP 954/2020 surge e, é para o pedido nela contido, para o problema que ela criou, que será necessário encontrar uma resposta. Como mencionado, o processo natural previsto inclusive pela LGPD, é que o compartilhamento de dados pessoais com o Estado seria possível quando se destinasse à políticas públicas. Bem, a MP mencionou qual o destino que pretendia para os dados pessoais.

Em resposta ao questionamento, Leandro Karnal lembrou da Crise de 1929 dos EUA, em que o presidente Franklin D. Roosevelt implantou estatais, organismos de buscas de empregos e ações concretas como a Companhia do Vale do Rio Tennessee, mas que também teria multiplicado os mecanismos de controle. Comentou que no Brasil alguns dos mecanismos de controle, a exemplo dos Tribunais de Contas, às vezes, infelizmente estão envolvidos em escândalos. Para Karnal, em um país onde o sensor se tornou imoral ou eticamente duvidoso é preciso que as estruturas que controlam os atos do governo em nome do Estado se multipliquem. A preocupação do CFOAB se justifica também pela necessidade de controle do poder, ainda que a MP 954/2020 disponha que os dados pessoais não serão compartilhados e que após o uso serão eliminados (BRASIL.e, 2020, art.

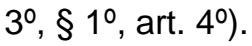

Karnal faz referência ao axioma "todo poder corrompe e o poder absoluto corrompe absolutamente" (CNN BRASIL, 2020). Portanto, opina que este seria o momento em que o Estado precisaria de mais interferência e vigilância, "[...] não porque ele seja desonesto, mas porque ele representa o interesse de todos, e o que é público tem que ser vigiado por todo mundo, não porque os governantes sejam particularmente honestos e desonestos, mas como lembra Rousseau quando trata do contrato social, é da natureza humana buscar o seu bem estar imediato e buscar o benefício dos seus, e a democracia é o único sistema que permite que eu coíba um pouco desse egoísmo (...)." 6

Sigamos adiante.

\subsection{Da contestação do direito fundamental à privacidade}

Há um círculo de proteção em relação ao indivíduo no que tange ao direito fundamental à privacidade. Contudo, embora a proteção deva ser compreendida como absoluta, existem situações que esse círculo precisa ser rompido (rompido e não invadido - esse tópico será retomado adiante) em prol de um interesse ainda maior, de um direito que se sobreponha ao indivíduo. No caso das

\footnotetext{
${ }^{6}$ CNN BRASIL. Op. cit. Intervalo da fala: 1:11:56' a 1:15:35'.
} 
questões envolvendo MP 954/2020, o direito que se sobrepõe ao da privacidade é o direito à vida do grupo social brasileiro, inclusive daqueles que terão seus dados captados.

Contudo, nenhum direito fundamental é inatingível. Nesse momento de pandemia até o direito à vida está sendo relativizado. Diante da falta de leitos em UTI para atender a todos que necessitam será necessário fazer uma escolha. Os noticiários relatam as decisões extremas que serão tomadas. (MARI, 2020).

A CF/88 menciona que a desconsideração da privacidade é permitida em determinadas condições, principalmente por autorização judicial como recordou a ADI 6.387 proposta pelo CFOAB. Mas, será que o momento atual permitiria tal normalidade, apesar da rapidez com que o Judiciário tem agido em situações envolvendo a COVID-19? E se um ministro decidir pedir vista de um processo? Quanto tempo será necessário esperar? Haverá tempo hábil para tal? Dados estatísticos permitem a visualização, ainda que parcial, de um cenário para tomada de decisões que na atualidade implica em mais óbitos, mais contaminações ou mais vidas. São escolhas difíceis e recheadas de consequências inclusive negativas para o administrador público, principalmente quando se depende de votos para se manter no cargo.

A princípio o que pode ser observado a partir dos comandos da MP debatida é que não se trata de quebra de privacidade, mas da transferência de dados específicos das empresas de telecomunicações prestadores de Serviço Telefônico Fixo Comutado e de Serviço Móvel Pessoal com a Fundação IBGE. Os dados requeridos, nos termos do art. $2^{\circ}$ são nomes, números de telefone e dos endereços de seus consumidores, pessoas físicas ou jurídicas. Em um estado democrático, como pretende o sistema brasileiro, não se permitiria em período de normalidade a sustentação de tal medida provisória, pois “(....) os poderes do Estado encontram, nos direitos e garantias individuais, limites intransponíveis, cujo desrespeito pode caracterizar ilícito constitucional." (BRASIL. STF. HC 126.454, p.5)

Ainda, é correta a observação do Ministro Celso de Mello , quando menciona que "não se pode ignorar que o direito à intimidade (e, também, o direito à privacidade) - que representa importante manifestação dos direitos da personalidade - qualifica-se como expressiva prerrogativa de ordem jurídica que consiste em reconhecer, em favor da pessoa, a existência de um espaço indevassável destinado a protegê-la contra indevidas interferências e intrusões de terceiros na esfera de sua vida privada." (BRASIL. STF. HC 126.454, p.2). Mas, a pergunta novamente que se faz é: qual o direito que a sociedade brasileira quer garantir, principalmente aos mais vulneráveis: a vida ou a privacidade? A existência para os excluídos e invisíveis sociais, acostumados a viverem à margem de direitos, a vida, por pior que seja, é o único bem verdadeiramente seu, pois muitos nem registro de nascimento possuem. Portanto, a quem interessa realmente o conflito de direitos tão gigantescos como os mencionados.

De qualquer forma, é preciso manter a vigilância em relação aos atos do Governo, seja ele qual for. Nesse sentido, vale mencionar a fala do Ministro Celso de Mello (BRASIL. STF. HC 126.454, p.2) sobre esse equilíbrio tão necessário em termos de direitos fundamentais:

É certo que a garantia constitucional da intimidade (e da privacidade) não tem caráter absoluto. Na realidade, como já decidiu esta Suprema 
Corte, "Não há, no sistema constitucional brasileiro, direitos ou garantias que se revistam de caráter absoluto, mesmo porque razões de relevante interesse público ou exigências derivadas do princípio de

convivência das liberdades legitimam, ainda que excepcionalmente, a adoção, por parte dos órgãos estatais, de medidas restritivas das prerrogativas individuais ou coletivas, desde que respeitados os termos estabelecidos pela própria Constituição" (MS 23.452/RJ, Rel. Min. CELSO DE MELLO). Isso não significa, contudo, que o estatuto constitucional das liberdades públicas - nele compreendida a garantia

fundamental da intimidade e da privacidade - possa ser arbitrariamente desrespeitado por qualquer órgão do Poder Público. (STF, Boletim 189, p. 3). [g.n.]

E continua o Ministro em seus argumentos:

Tenho insistentemente salientado, [...] que a tutela jurídica da intimidade (e, também, da privacidade) constitui - qualquer que seja a dimensão em que se projete - uma das expressões mais significativas em que se pluralizam os direitos da personalidade. Trata-se de valor constitucionalmente assegurado (CF, art. 5ํ, X), cuja proteção normativa busca erigir e reservar, sempre em favor do indivíduo - e contra a ação expansiva do arbítrio do Poder Público - uma esfera de autonomia intangível e indevassável pela atividade desenvolvida pelo aparelho de Estado. (BRASIL. STF. HC 126.454, p.3). [g.n.]

Bem, diante da atual crise sanitária, como criar um espaço no qual há respeito pela privacidade do indivíduo e por conseguinte do livre desenvolvimento da sua personalidade, de tal forma que as linhas dos círculos concêntricos (teoria desenvolvida por Heinrich Hubmann, a partir de 1953 na Alemanha), possam ser afrouxadas (não violadas) e cedam informações ao poder público? Esse é o problema desse estudo.

\section{DO PRINCÍPIO DA SOLIDARIEDADE}

Como mencionado o valor liberdade é muito caro para o ser humano, mas tal bem somente foi conquistado por conta da união dos indivíduos para que a mesma se concretizasse. Com a liberdade, foi possível garantir que aspectos íntimos do ser fossem mantidos dentro do aspecto da privacidade, longe dos olhos curiosos e inclusive do Estado.

Neste momento da epidemia da COVID-19 os princípios da privacidade e liberdade precisam ser revistos e relativizados em razão de um bem ainda maior, as vidas da espécie humana. As palavras de Supiot vão de encontro ao argumento mencionado:

Para ser livre, o sujeito de direito deve primeiro estar vinculado (sub-jectum: lançado embaixo) por palavras que o prendam aos outros homens. Os vínculos do Direito e os vínculos da palavra se mesclam, assim, para que cada recém-nascido tenha acesso a humanidade, ou seja, para atribuir à sua vida um significado, no duplo sentido, geral e jurídico, dessa palavra. Cortado de todo vínculo com seus semelhantes, o ser humano é fadado à idiotia, no sentido etimológico do termo (grego ídios: "que está restrito a si mesmo"). Fica igualmente ameaçado de idiotia quem, fechado em sua própria visão do mundo, é incapaz de compreender que há outras possíveis, 
ou seja, incapaz de se acertar com seus semelhantes sobre uma representação do mundo em que cada qual tenha seu lugar certo. (SUPIOT, 2007, p. VIII, Prólogo).

A quem, especificamente cada brasileiro está vinculado? A outros brasileiros como ele, inclusive, com a memória daqueles que já morreram em decorrência da pandemia que assola o país neste ano de 2020. São os vínculos inclusive do Direito que permitem a pessoa, logo ao nascer, que tenha acesso a humanidade e, se cortado de "todo vínculo com seus semelhantes" (SUPIOT, 2007, p. VIII, Prólogo), como mencionado por Supiot, ele está condenado a idiotia, isto é, restrito a si mesmo. Se fechado em si mesmo, em seu egoísmo, esquece de um elemento básico, a solidariedade, princípio presente na Constituição Federal, assim como o princípio da Dignidade da Pessoa Humana, que é inclusive um dos fundamentos da República, que quer se firmar como Estado Democrático de Direito.

A solidariedade, se observada não como um princípio jurídico, mas como um compromisso com o outro, assume neste período de crise sanitária outros contornos que vão além de ações de bondade em relação ao próximo. Karnal, ainda na entrevista, responde a jornalista Mari Palma que "solidariedade é uma estratégia, é uma estratégia de vida, não é possível imaginar-se em uma cidadela sitiada [...]. A solidariedade hoje é um gesto estratégico e um gesto de inteligência. [...]"7 A vida de cada um está ligada e dependente das ações e cuidados da vida do outro e, se ele não conseguir se manter sozinho, a sociedade precisará ajudar, caso contrário será dizimada.

A solidariedade foi jurisdicionalizada e se tornou um dos objetivos fundamentais da República Federativa, insculpida no art. 3ำ, inciso I da CF/88 (BRASIL, 1988), vale dizer, não se trata apenas de dever ético, de simples caridade que pode ser aderida ou não pelo indivíduo. Não é uma escolha, mas um objetivo que deve ser seguido por todos àqueles que estão sob a tutela do Estado brasileiro. Takoi explica que "a solidariedade é a expressão de um valor político novo que defende e tutela tanto os bens individuais, como os coletivos. É a demonstração de compromisso dos sacrifícios compartilhados." (TAKOI, 2011, p.3)

Com a presença da pandemia, quando o Brasil já registra mais de 12.000 mil mortos (14/05/20), é preciso proteger a vida, bem como o que a envolve, e assim olhar para o amanhã, pós COVID-19. É preciso blindar a dignidade humana e o feixe de direitos que dela irradiam, e que para elas retornam, para a materialização da personalidade, como a privacidade de dados pessoais. A dignidade deve ser protegida pela solidariedade da própria humanidade, conforme menciona Takoi (2011, p.3) e, é essa a ideia que deve guiar a sociedade nesse momento de crise mundial. A "solidariedade pode ser entendida no sentido de pertença, ou seja, de partilha e de coresponsabilidade de todos os seres humanos à sorte ou vicissitudes dos demais (solidum, soldum=inteiro, compacto)." (TAKOI, p.3). O pertencer é o estar vinculado para então estar livre. Por pertencer a humanidade, por estar vinculado a ela, a existência de cada um dependerá de quanto estrategicamente seremos solidários uns com os outros.

Nesse sentido, em um primeiro momento, o compartilhamento de dados pessoais dos brasileiros com o poder público, a fim de ser utilizado no desenvolvimento de pesquisas para auxiliar

${ }^{7}$ CNN BRASIL. Op. cit. Intervalo da fala: 35:25' - 38:15'.

Revista do Direito [ISSN 1982-9957]. Santa Cruz do Sul, n. 64, p. 91-111, maio-ago. 2021. https://online.unisc.br/seer/index.php/direito/index 
no controle da COVID-19 é uma medida adequada. Mas, como não poderia deixar de ser, a questão é: qual a segurança que o particular tem de que os seus dados não serão compartilhados indevidamente causando-Ihe dano ao seu patrimônio moral e financeiro?

\section{DO DIREITO À PRIVACIDADE EM CONTEXTOS DE ANORMALIDADE E A MP 954/2020}

"A chave para o sucesso do enfrentamento à pandemia é o timing para tomar as decisões corretas. E o tempo está correndo. Tic, tac." (Deco Bancillon)

Antes de iniciar a exposição do tópico, se faz necessário algumas informações prévias que delimitam o objeto do estudo que adiante se apresentará. A LGPD (BRASIL, 2018) informa no art. 5o o que é dado pessoal, dado pessoal sensível e dado anonimizado.

I - dado pessoal: informação relacionada a pessoa natural identificada ou identificável;

II - dado pessoal sensível: dado pessoal sobre origem racial ou étnica, convicção religiosa, opinião política, filiação a sindicato ou a organização de caráter religioso, filosófico ou político, dado referente à saúde ou à vida sexual, dado genético ou biométrico, quando vinculado a uma pessoa natural;

III - dado anonimizado: dado relativo a titular que não possa ser identificado, considerando a utilização de meios técnicos razoáveis e disponíveis na ocasião de seu tratamento.

A Serpro apresenta como dado pessoal a informação que

[...] permite identificar, direta ou indiretamente, um indivíduo que esteja vivo, então ela é considerada um dado pessoal: nome, RG, CPF, gênero, data e local de nascimento, telefone, endereço residencial, localização via GPS, retrato em fotografia, prontuário de saúde, cartão bancário, renda, histórico de pagamentos, hábitos de consumo, preferências de lazer; endereço de IP (Protocolo da Internet) e cookies, entre outros. (SERPRO, 2020).

Há uma Proposta de Emenda Constitucional, a PEC 17/2019 que pretende acrescentar "[...] o inciso XII-A, ao art. 5ㅇ, e o inciso XXX, ao art. 22, da Constituição Federal para incluir a proteção de dados pessoais entre os direitos fundamentais do cidadão e fixar a competência privativa da União para legislar sobre a matéria." A ementa da PEC informa que "assegura o direito à proteção de dados pessoais, inclusive nos meios digitais. Inclui entre as competências da União legislar sobre proteção e tratamento de dados pessoais." (BRASIL.c, 2019). Após aprovação pelo plenário do Senado Federal (02/07/2019), a proposta foi encaminhada à Câmara dos Deputados em 03/07/2019. Até o dia 14/05/2020 a proposta ainda lá continuava.

É legítima a preocupação dos estudiosos e juristas do tema proteção de dados pessoais, de que o compartilhamento proposto pela da MP 954/2020, tem potencial para gerar danos irreversíveis aos proprietários de tais informações. Percebe-se uma invasão do Estado na privacidade dos cidadãos e a história que conta os fatos, mostra que empreendimentos totalitários se iniciam a partir da dominação dos indivíduos. Não se está aqui afirmando que a MP tem motivos diferentes daqueles 
mencionados nela própria ou na sua exposição, mas sim que a democracia brasileira é jovem e precisa de atenção redobrada.

Os direitos fundamentais inscritos na $\mathrm{CF} / 88$ refletem uma longa caminhada que precede inclusive o Estado brasileiro. Povos lutaram pela liberdade, pelo direito de não serem vigiados ou terem a sua privacidade rompida, pela sua autodeterminação, pelo direito do livre desenvolvimento de suas personalidades, pela expressão dos seus pensamentos.

Com o avanço da tecnologia e todas as suas benesses, veio também o nascimento de gigantescos bancos de dados que substituíram os espaços físicos de outrora, papeis, fichas ou arquivos. Milhares de informações são guardadas pelo ente público ou privado em ambiente online e que podem ser transferidas de um portador para outro em segundos. Essa é a realidade que se apresenta e é para ela que os conceitos de proteção de dados ou compartilhamentos precisam ser pensados e construídos, principalmente no cenário atual da COVID-19, quando acabou por acelerar a necessidade de se estar em rede.

A pandemia que acomete todo o globo terrestre tem ceifado milhares de vidas. Em razão da dramaticidade por onde o vírus chega, se instalou verdadeiro Estado de anormalidade, como foi a determinação da MP 954/2020. O panorama que ela indica é que a proteção de proteção de dados tradicional é suspensa, isto é, a rede de proteção legal é afrouxada e o Estado invade o direito de personalidade do indivíduo e capta os dados que the interessam para o fim que deseja. A invasão somente é possível pois é ilegítima, embora legal vez que amparada em norma. ${ }^{8}$

A preocupação do artigo é a mesma que ocupa outros estudiosos. A Data Privacy Brasil produziu o "Relatório Privacidade e Pandemia: recomendações para o uso legítimo de dados no combate à COVID-19". O documento informa que independente da vigência da LGPD, "as partes envolvidas em ações dessa natureza possuem o dever de incorporação de salvaguardas e mecanismos de mitigação de riscos a direitos fundamentais, decorrente do ordenamento jurídico brasileiro." (BIONI; ZANATTA; et al, 2020, p. 3). [g.n.]

As recomendações se dividem em cinco passos que sugerem estar presentes nos processos decisórios. São eles: (1) Avaliação da necessidade da elaboração de política de saúde centrada em dados; (2) Definição da finalidade e necessidade do tratamento de dados; (3) Definição do ciclo de vida e descarte; (4) Definição de salvaguardas específicas para direitos fundamentais; (5) Garantia de publicidade, transparência e participação. (BIONI; ZANATTA; et al, 2020, p. 6). Para a presente pesquisa se destacam os itens 1 e 4 .

O Relatório informa que ao longo desses cinco passos, 10 princípios foram identificados, os quais devem ser observados em cada etapa do processo, quais sejam: motivação fundamentada; amparo em autorização legal; formalização em instrumento jurídico; definição de finalidade específica de forma expressa e seu subprincípio: Vedação do uso com finalidades lucrativas e discriminatórias abusivas; limitação ao mínimo necessário; definição do ciclo de vida dos dados e seu subprincípio: limitação temporal, exclusão posterior ao uso adequado, qualidade dos dados; (pseudo)anonimização de forma a garantir baixos riscos de reidentificação de pessoas e seu subprincípio: Compromisso de

8 As discussões que envolvem a ADI indicam que a MP não preenche os requisitos formais e materiais exigidos para a legalidade da norma. De qualquer forma, referida análise não é objeto do estudo, portanto, será preciso aguardar o desfecho da demanda. 
não reidentificação pelo recipiente, priorização da informação (output) e o não repasse de dados (input), Inclusão de recipientes terceiros confiáveis caso seja necessária a agregação de base de dados, não divulgação de identidade de recuperados, infectados ou suspeitos; garantia de segurança da informação; transparência ativa; preferência por aplicativos e tecnologias de código aberto. (BIONI; ZANATTA; et al, 2020, p. 6).

Pretende-se comentar alguns dos passos e princípios. Trazer o pensamento dos autores e cooperar com os nossos.

O primeiro passo mencionado pelos autores refere-se a "necessidade de fundamentação técnica e científica quanto à necessidade e eficiência do uso de dados pessoais".

Comentam que "deve-se garantir que tais ações sejam motivadas e respaldadas em evidências técnicas e científicas quanto à necessidade e eficiência do uso de tais informações". A MP não deixa claro de que forma os dados poderiam contribuir para as políticas públicas envolvendo a COVID-19. Por outro lado, é difícil nesse momento em que a epidemia ainda evolui e se torna estudada, contar com protocolos seguros que possam dar sustentação científica à MP.

É possível encontrar algumas informações sobre o tratamento de dados pessoais no art. 46, do Regulamento Sanitário Internacional, aprovado pelo Decreto 10.212/2020 e no art. 6oㅡ, da Lei 13.979/2020 (“Lei da Quarentena”). Entretanto, essas normas se destinam a proteção de dados das pessoas infectadas por pandemias, no caso em tela pela COVID-19, como descritos pelos artigos das normas respectivos expostos na nota de rodapé. A situação que envolve a MP 954/2020 demonstra que ela requer os dados de todos os brasileiros que estão no banco de dados das teles. As normas mencionadas podem ser utilizadas mais como um elemento de interpretação hermenêutica no que tange a proposta de proteção de dados pessoais.

Por conseguinte, a Exposição de Motivos da MP 954/2020, informa que o compartilhamento de dados de empresas de telecomunicações com o Poder Público teria como fim dar suporte a "produção estatística oficial, com vistas ao levantamento de dados para as pesquisas estatísticas do IBGE, incluindo o monitoramento da pandemia associada ao COVID-19". Percebe-se neste trecho que o monitoramento da pandemia estaria em segundo plano. Reconhece-se a importância das pesquisas do IBGE, mas o tema não precisaria se utilizar do instrumento de MP.

Bem, mas como a pandemia mudou a vida e nos colocou em distanciamento/isolamento social, o IBGE decidiu "suspender temporariamente todas as entrevistas e coletas de dados presenciais realizadas no âmbito das pesquisas que compõem o plano regular de trabalho do instituto." (Brasil.d, 2020). E, tendo em vista a importância das "atividades de produção estatística, inclusive para o enfrentamento da pandemia" (Brasil.d, 2020) [g.n], foi necessário, como relata a Exposição dos Motivos a adoção de alternativas para a continuidade das pesquisas, que obviamente são fundamentais para a implementação de políticas públicas. Sim, é óbvio que o país precisa dos dados estatísticos do IBGE para a tomada de decisões, mas, sem um plano estratégico específico de como a continuidade das pesquisas, que então passariam a se utilizar de todos os dados pessoais dos brasileiros contidos nos bancos de dados das teles, "inclusive" para o combate a pandemia, não foi claro. 
Dessa forma, "a Pesquisa Nacional por Amostra de Domicílios Contínua (PNAD Contínua), que consiste na maior operação estatística domiciliar empreendida regularmente pelo IBGE, com mais de 200 mil domicílios pesquisados a cada trimestre" (Brasil.d, 2020), estaria impedida de acontecer e era necessário que alguma medida fosse adotada. Assim, de acordo com a Exposição, vislumbrou-se "como alternativa imediata a substituição temporária da coleta presencial pela coleta através de telefone, de modo que sejam garantidas as entrevistas e mantidas as séries históricas da pesquisa" (Brasil. $d, 2020$ ). Apesar de fundamental, pesquisa poderia ser adiada, sendo que tal conduta não seria a primeira vez a acontecer. Na ADI 6387, o CFOAB faz menção a matéria jornalística que relata o adiamento.

Continua o documento argumentando que a garantia de realização da "PNAD Contínua reveste-se de especial relevância" uma vez que "a pesquisa deverá ser veículo para a inclusão de quesitos relacionados ao monitoramento da pandemia de COVID-19 em todo o território nacional, orientando políticas públicas e o processo decisório nas mais distintas esferas" (BRASIL.d, 2020). Também, que "possibilitará o levantamento de dados representativos para diferentes níveis geográficos e de segmentos socioeconômicos" (BRASIL.d, 2020). Ora, nem mesmo a Exposição de Motivos informa quais são os quesitos que serão utilizados para o monitoramento da pandemia. Não se juntou à exposição nenhum plano estratégico que validasse eventuais políticas públicas ou como os dados requeridos teriam importância no processo.

O que se infere da Exposição dos Motivos e da própria MP 954/2020 é que nenhum planejamento existia quanto a maneira como os dados seriam utilizados, quais eram os recursos disponíveis para tanto ou qual (quais) o (s) órgão (órgãos) do governo seriam os responsáveis pelas políticas públicas de combate à COVID, a partir do momento em que o IBGE estivesse com as informações requeridas.

A privacidade do indivíduo é um direito fundamental e da personalidade, que embora sujeito a relativização, deve ocorrer apenas, ou nas condições previstas na Constituição ou diante de situação de extrema necessidade, como de fato é a situação da pandemia. Contudo, devem ser observados os critérios de razoabilidade, proporcionalidade, segurança jurídica, legalidade, legitimidade, transparência, moralidade, eficiência, enfim... Apenas o princípio da legalidade foi observado, entretanto, apenas em um primeiro momento, pois a MP de fato instrumentaliza a determinação do compartilhamento dos dados pessoais. Todavia, quando a luz da verdade é lançada sob a MP, evidencia-se de imediato que a mesma padece de inconstitucionalidade, vez que não atende os requisitos do art. 62 da Constituição Federal. ${ }^{9}$

Ainda a Exposição dos Motivos da MP, a qual é revestida de requisitos formais e materiais específicos, informa que "a introdução de entrevistas por meio não presencial poderá contribuir para inovações futuras nos métodos de coleta dessa pesquisa e dos demais levantamentos realizados pelo IBGE, com vistas à manutenção de seu padrão de qualidade com crescente eficiência e economicidade" (Brasil, 2020). Uma medida provisória não se presta a testes de novas formas de

9 Art. 62. Em caso de relevância e urgência, o Presidente da República poderá adotar medidas provisórias, com força de lei, devendo submetê-las de imediato ao Congresso Nacional. Aspectos constitucionais da MP não são objeto do Estudo. Não é objeto do presente estudo tratar dos detalhes constitucionais da legitimidade da MP. 
entrevistas para o IBGE. Tal discussão poderia ocorrer por meio de lei, decreto ou regulamentos internos do próprio IBGE, mas, com vagar, sem afobamentos ou atropelos a direitos e garantias fundamentais, além do congestionando da pauta de votação do Congresso Nacional em momento tão delicado como o presente. No entanto, a MP deixa muito explícito que quer ter acesso aos dados pessoais. Para uma invasão dessa monta na privacidade do indivíduo, certamente caberia uma consulta pública e agora, por conta da ADI 6387 (BRASIL.i., 2020) proposta em face da MP 954/2020, haverá oportunidade para tanto.

Informações digitais e nesse contexto inserimos os Dados pessoais, são o novo petróleo do século $X X I$, com a diferença que esse novo ativo não se esgota e aumenta a cada segundo. $O$ governo quer ter acesso ao este recurso, entretanto, precisa informar como o utilizará. A Exposição dos Motivos traz três objetivos pouco convincentes que justificariam a urgência da Medida Provisória, mas, como já mencionado, pouco esclarece como os dados pessoais serão utilizados.

É mister frisar que a edição da referida Medida Provisória coloca-se como urgente diante de três fatos objetivos, quais sejam: 1) a necessidade da produção tempestiva de dados para o monitoramento da pandemia de COVID-19; 2) a necessidade de garantir a continuidade da PNAD Contínua, com a natural preservação de suas séries históricas básicas, úteis à gestão e avaliação de políticas públicas em âmbito nacional; 3) a tempestividade necessária para a obtenção dos dados requeridos junto às empresas de telecomunicações, supondo-se que uma Medida Provisória terá eficácia mais significativa se comparada a quaisquer outras normas ou instrumentos de solicitação dos dados. (Brasil, 2020).

A partir da análise da Exposição de Motivos, percebe-se que os fundamentos para a criação da MP são frágeis e não se revestiriam de características fundamentais como relevância e urgência. $\mathrm{Na}$ ADI 6387 (BRASIL.i, 2020) o AGU informou que os dados pessoais seriam utilizados para o PNAD, entretanto, o texto da MP nada diz a esse respeito, logo, em desacordo com a própria Exposição.

De qualquer forma, o Plenário do Supremo Tribunal Federal (STF), votou pela manutenção de liminar que suspendeu a eficácia da MP 954/2020, que prevê o compartilhamento dos dados pessoais durante a pandemia da COVID-19.Por outro lado, no dia 4 de maio de 2020 o IBGE anunciou que daria início a realização da PNAD Covid, com foco na evolução da doença. A pesquisa é uma parceria do IBGE com o Ministério da Saúde e dois mil agentes ligarão para 193, 6 mil domicílios em 3.364 cidades em todo o território nacional. Essa situação foi observada pela Ministra que a mencionou em sua decisão. Provavelmente a MP foi desnecessária uma vez que o problema foi resolvido de outra forma. A privacidade de milhares de brasileiros foi resguardada e o tema continuará a ser discutido no STF. Em breve estará disponível uma decisão que guiará com segurança o administrador público, bem como particulares.

Do Relatório Privacidade e Pandemia, o passo 2 é outo tópico que merece destaque nesse estudo. Menciona que "todas as medidas empregadas devem se pautar pela menor intrusão à privacidade possível" (BIONI; ZANATTA; et al, 2020, p. 7).

A MP requer o compartilhamento dos nomes, dos números de telefone e dos endereços de seus consumidores, pessoas físicas ou jurídicas. Qual a relevância de todos esses dados para a 
pesquisa? A dúvida não foi esclarecida nem na Exposição dos Motivos e tão pouco na MP. Apenas justificativas genéricas. Então, a pergunta que se faz é se haveria real necessidade de todas as informações requeridas, ou se os dados anonimizados ou pseudonimizados já não atenderiam as necessidades da pesquisa? Também, se para a execução do Pnad (informado apenas na Exposição dos Motivos) se utiliza da amostragem, por que então um volume excessivo de dados a serem compartilhados?

Não se discute aqui a integralidade moral do IBGE, mas o descabimento do pedido da MP para uma comunicação de dados tão gigantesca, sem a apresentação de qualquer plano estratégico de segurança desse compartilhamento e especificamente como será utilizado. As justificativas foram genéricas o que por certo não justifica a invasão à privacidade dos clientes das teles, os quais, necessariamente, não representam todos os brasileiros. Diversas reportagens mostraram que alguns dos brasileiros invisíveis e excluídos não tinham acesso a telefone ou internet e vezes não dispunham nem mesmo de documentos pessoais essenciais como certidão de nascimento. (G1, 2020).

Tal requerimento previsto pela MP invade o primeiro dos círculos de proteção da privacidade, conforme exposto pela Teoria dos Círculos Concêntricos, de Heinrich Hubmann. Contudo, diante de um vazamento dos dados pessoais, a invasão poderá chegar aos dois círculos mais íntimos, qual seja, intimidade e sigilo. E diante de referido risco não houve preocupação com as salvaguardas para manter a integridade e integralidade do compartilhamento.

Pequenos detalhes ou melhor, diversos dados ainda que isolados, se artificialmente juntados podem levar a alguma resposta. Nesse ponto nos valemos da Teoria do Mosaico para explicar o argumento.

Em uma democracia jovem como a brasileira, sempre há a tentativa de domínio das massas. Aqui não se está falando deste ou daquele governo, mas sim da necessidade de vigilância e segurança em relação ao poder de manipulação do grupo social em prol de uma ideologia, seja ela qual for. Imagine quantas notícias falsas podem ser disparadas em segundos a partir das informações colhidas. Por essa razão, quando se trata de dados pessoais todo o cuidado é pouco. A LGPD já menciona que "as atividades de tratamento de dados pessoais deverão observar a boa-fé" e princípios como o da necessidade (art. 6ํㅡㄹ III) que estabelece a "limitação do tratamento ao mínimo necessário para a realização de suas finalidades, com abrangência dos dados pertinentes, proporcionais e não excessivos em relação às finalidades do tratamento de dados. (BRASIL.b, 2018).

Do exame da teoria do mosaico, proposta por Fulgencio Madrid Conesa, percebe-se que a informação não se torna relevante simplesmente porque está na esfera do sigilo. Partindo de uma análise sob o viés do domínio sobre o corpo do indivíduo, um inocente dado, talvez da esfera da privacidade em conexão com outro, não menos importante, pode revelar elementos, sobre a personalidade a ponto de expô-lo, sem a sua autorização e agressivamente invadir sua personalidade. É o que afirma Conesa: "al igual que ocurre con las pequenas piedras que forman los mosaicos, que en si no dicen nada, pero que unidas pueden formar conjuntos plenos de significado." [g.n]. (BESSA, 2003, p. 91 apud MAIA, 2020).

Assim, para a pergunta: quais dados podem ser captados, a resposta é: o mínimo possível para que a atividade pretendida pelo prestador ou vendedor se concretize. Em termos de relação com 
o poder público, a resposta é a mesma: captação do mínimo possível, apesar que nesse ponto se deve fazer uma ressalva. É lógico que em um futuro não distante, o Brasil também adote algum sistema de identidade digital, a exemplo da Índia. (GONZÁLEZ, 2020).

Isto posto, em termos jurídicos para que se tenha uma clarificação ou um mapa mental da forma como se deve cuidar o tema privacidade, dados, direitos da personalidade e fundamentais e obter respostas coerentes diante de casos concretos, é preciso analisá-los sob o viés da teoria dos círculos concêntricos e também secantes, alinhada a teoria do mosaico de Conesa. Cada segmento de atividade tem suas necessidades específicas de dados. O ideal é que cada um deles crie políticas/protocolos que comportem tais diferenciações e gerem para os envolvidos a segurança digital necessária quanto ao armazenamento de dados.

O relatório apresenta o Passo 4: Definição de salvaguardas específicas para direitos fundamentais".

Este tópico é fundamental para a garantia dos direitos fundamentais e da personalidade, em especial ao da privacidade, no que tange a dados pessoais. O documento menciona a necessidade de Medidas de contenção a riscos, uma vez que "toda e qualquer atividade de tratamento de dados carrega consigo riscos à privacidade dos seus titulares" (BIONI; ZANATTA; et al, 2020, p. 8). Exemplifica algumas delas como "técnicas de (pseudo)anonimização, passando por segregação ou, ao menos, agregação de base de dados com filtros (recipientes confiáveis), chegando ao estabelecimento de medidas robustas de segurança da informação". (BIONI; ZANATTA; et al, 2020, p. 8).

Deve-se observar a limitação temporal do uso dos dados e isso a MP 954/2020, deixou bem claro que seria durante o período da pandemia. Essa autorização alargada tem um óbice: não se sabe quando a crise sanitária chegará ao fim ou amenizada para que haja a suspenção do compartilhamento de dados. Diante da referida abertura os dados ficarão enclausurados pelo IBGE e, a exemplo de um canivete suíço, poderão ser utilizados basicamente para tudo com o agravo do tempo que expõe a riscos de sequestro esse bem tão precioso para a modernidade.

No que tange a anonimização dos dados, o Relatório defende que nesse caso como também no da pseudo(anominização), deve-se cuidar para que não haja a possibilidade da Reindenficação. A LGPD menciona que na anonimização se deve observar a questão da temporariedade e da disponibilidade de recursos técnicos da época. Se atualmente já se sabe que será possível a reindentificação do indivíduo, em razão do progresso tecnológico, então por que hoje, pensando no futuro, não se colhe apenas o que se irá utilizar.

Outro ponto de destaque do relatório é para proibição de monetização de dados sensíveis ou uso para quaisquer outras finalidades além das necessárias para o combate à pandemia (BIONI; ZANATTA; et al, 2020, p.11). Esse ponto é o ideal, mas o vazamento de dados, quem controla? Ninguém. Embora o relatório não mencione, garantirá o pagamento de eventuais dados.

\section{CONSIDERAÇÕES FINAIS}


A COVID-19 está causando sérios problemas por onde tem surgido. Em 29/05/2020 as notícias que chegam à população é que o pico de contaminação ainda não atingiu o seu cume. Em alguns estados que conseguiram se organizar previamente e com eficiência, os danos não foram significativos em termos econômicos e pessoas. A economia está comprometida, apesar do apoio que os governos têm oferecido as pessoas e empresas. Estabelecimentos comerciais, com exceção dos serviços essenciais, foram fechados. Em alguns locais do país o sistema de saúde já entrou em colapso. Não há leitos, medicamentos, respiradores ou equipamentos de proteção suficientes. As disputas para a aquisição de bens e produtos no mercado internacional estão acirradas e não há para todos os países ao mesmo tempo. Por vezes, ainda o que se adquire é adulterado e nesse vai e vem, outras vidas se perdem.

Da forma como a MP 954/2020 foi criada é evidente que padece de vícios, principalmente no que tange a urgência. Contudo, com a propositura da ADI o país terá uma oportunidade para debater o tema com amplitude. Serão ouvidos diversos segmentos da sociedade que traçarão algumas alternativas para situações que envolvem a necessidade de captação de dados de particulares sem prévia autorização.

Então, como proceder em situações como a presente que exigem, de um lado, uma ação rápida do governo que necessita de dados para a elaboração de políticas públicas, de outro o direito à privacidade do indivíduo.

Bem algumas ponderações podem ser indicadas para esse assunto tão sensível.

A utilização de Medida Provisória é lícita e deve ser utilizada com parcimônia. Em casos polêmicos e delicados como o da MP 954/2020 que envolve privacidade de dados pessoais, certamente é preferível a intervenção do Congresso Nacional para que a legitimidade possa estar melhor fundamentada.

Mas, seja lá qual a forma escolhida para a captação de dados é essencial que previamente tenham sido formuladas salvaguardas técnicas para todo o processo de compartilhamento, manuseio e guarda, isto é, segurança cibernética. Em termos jurídicos, se o objetivo é a utilização das informações para o desenvolvimento de políticas, é básico que se apresente qual o modelo que se pretende trabalhar, detalhes de administração. Não se adquire insumo (no caso dados) sem saber qual o destino que se dará a ele. Ação pratica dessa forma coloca em risco direitos fundamentais e implica em falta de planejamento e gastos desnecessários, o que fere o princípio constitucional da eficiência (art. 37, caput, CF/88).

Logo, não se está aqui afirmando que a MP 954/2020 não deveria ter sido proposta. Defende-se que o governo pode solicitar tais informações, mesmo porque o país está inserido em uma crise sanitária aterrorizadora e a população brasileira precisa muito do Governo neste momento. Assim, da mesma forma que não é fácil acreditar que um elefante em uma loja de cristais não causará danos, também não é crível que a MP 954/2020 oferece segurança suficiente para a privacidade dos indivíduos.

Nesse ponto, correta foi a decisão do STF, a qual não deve ser acusada de estar interferindo indevidamente nas ações do Poder Executivo. Como já mencionado, a ADI ocorre em 
momento oportuno, pois será possível que a discussão sobre o compartilhamento de dados seja discutida com amplitude pela comunidade científica e jurídica.

A conclusão final para esse trabalho é infelizmente informar que no dia 22/04/20 (quando se iniciaram as pesquisas), o site do Ministério da saúde registrava 45.757 casos confirmados e 2.906 mortes. Relatório da OPAS informava que até o dia 21/04/2020, foram confirmados no mundo: "2.397.216 casos de COVID-19 (...) e 162.956 mortes (...). Ao final do estudo, no dia 29/05/2020, o site do Ministério da Saúde no Brasil registrava 26.754 mortos e 438.238 casos confirmados (BRASIL.I, 2020). Não houve compartilhamentos de dados, o IBGE encontrou outra solução para as estatísticas e pessoas continuam morrendo.

\section{REFERÊNCIAS}

AUXÍLIO emergencial de $R \$ 600$ revela 46 milhões de brasileiros invisíveis aos olhos do governo. G1. 26 abril 2020. Disponível em: https://g1.globo.com/fantastico/noticia/2020/04/26/auxilioemergencial-de-r-600-revela-42-milhoes-de-brasileiros-invisiveis-aos-olhos-do-governo.ghtml. Acesso em: 26 maio 2020.

BANCILLON, Deco. Coronavírus: o que esperara das próximas semana. Congresso em Foco. 20 de abr. 2020. Disponível em: https://congressoemfoco.uol.com.br/opiniao/forum/coronavirus-o-queesperar-das-proximas-semanas/. Acesso em: 21 abr. 2020.

BRASIL.a. [Constituição (1988)]. Constituicão da República Federativa do Brasil de 1988. Brasília, DF: Senado Federal, 1988. Disponível em:

http://www.planalto.gov.br/ccivil 03/constituicao/constituicao.htm. Acesso em: 23 maio 2020.

BRASIL.b. Lei n. 13.709, de 14 de agosto de 2018. Lei Geral de Proteção de Dados Pessoais (LGPD). Disponível em:

http://www.planalto.gov.br/ccivil 03/ ato2015-2018/2018/lei/L13709.htm. Acesso em: 22 maio 2020.

BRASIL.c. Senado Federal. PEC 17/2019. Atividade Legislativa. Disponível em:

https://www25.senado.leg.br/web/atividade/materias/-/materia/135594. Acesso em: 14 maio 2020.

BRASIL.d. Exposição de Motivos da Medida provisória no 954, de 17 de abril de 2020. EM no 00151/2020 ME. Brasília, 15 de Abril de 2020. Disponível em:

http://www.planalto.gov.br/ccivil 03/ Ato2019-2022/2020/Exm/Exm-MP-954-20.pdf. Acesso em: 24 maio 2020.

BRASIL.e. MP 954, de 17 de abril de 2020. Dispõe sobre o compartilhamento de dados por empresas de telecomunicações prestadoras de Serviço Telefônico Fixo Comutado e de Serviço Móvel Pessoal com a Fundação Instituto Brasileiro de Geografia e Estatística, para fins de suporte à 
produção estatística oficial durante a situação de emergência de saúde pública de importância internacional decorrente do coronavírus (covid-19), de que trata a Lei oㅜ 13.979, de 6 de fevereiro de 2020. Disponível em: http://www.planalto.gov.br/CCIVIL 03/ ATO20192022/2020/MPV/MPV954.HTM. Acesso em: 22 maio 2020.

BRASIL.f. Decreto n. 10.212 de 30 de janeiro de 2020. Promulga o texto revisado do Regulamento Sanitário Internacional, acordado na 58ํㅗ Assembleia Geral da Organização Mundial de Saúde, em 23 de maio de 2005. Disponível em: http://www.planalto.gov.br/ccivil 03/ ato20192022/2020/decreto/D10212.htm\#anexo. Acesso em: 24 maio 2020.

BRASIL.g. Lei n. 13.979, de 6 de fevereiro de 2020. Dispõe sobre as medidas para enfrentamento da emergência de saúde pública de importância internacional decorrente do coronavírus responsável pelo surto de 2019. Disponível em: http://www.planalto.gov.br/ccivil 03/ ato20192022/2020/lei/L13979.htm. Acesso em: 24 maio 2020.

BRASIL.h. MP n. 959, de 29 de abril de 2020. Estabelece a operacionalização do pagamento do Benefício Emergencial de Preservação do Emprego e da Renda e do benefício emergencial mensal de que trata a Medida Provisória $n^{\circ}$ 936, de $1^{\circ}$ de abril de 2020, e prorroga a vacatio legis da Lei $n^{\circ}$ 13.709, de 14 de agosto de 2018, que estabelece a Lei Geral de Proteção de Dados Pessoais LGPD. Disponível em: http://www.planalto.gov.br/ccivil 03/ Ato2019-2022/2020/Mpv/mpv959.htm. Acesso: 22 maio 2020.

BRASIL.i. Supremo Tribunal Federal (STF). Processo n. 00905660820201000000 - ADI 6387 - Ação Direta de Inconstitucionalidade. DF. Reqte: Conselho Federal da Ordem dos Advogados do Brasil CFOAB. Intdo: Presidência da República. Rel. Min. Rosa Weber. Disponível em: http://portal.stf.jus.br/processos/detalhe.asp?incidente=5895165. Acesso em: 23 maio 2020 .

BRASIL.j. Ministério da Saúde. Sobre a Doença. Disponível em: https://coronavirus.saude.gov.br/sobre-a-doenca\#o-que-e-covid. Acesso em: 22 abr. 2020.

BRASIL.I. Ministério da Saúde. Covid-19. Painel Coronavírus. Atualizado em: 28/05/2020 - 20:18. Disponível em: https://covid.saude.gov.brl. Acesso em: 29 maio 2020.

BRASIL.m. Superior Tribunal de Justiça. HC 126454. Sigilo bancário - Quebra administrativa pelo Fisco - Inadmissibilidade - Exigência de ordem judicial. RE 601314/SP. Relator: Ministro Edson Fachin. Voto do ministro Celso de Mello.

BESSA, Leonardo Roscoe. O consumidor e os limites dos bancos de dados de proteção ao crédito. São Paulo: Editora Revista dos Tribunais, 2003. p. 91, apud MAIA, Luciano Soares. A privacidade e os princípios de proteção do indivíduo perante os bancos de dados pessoais. Disponível em: 
http://www.publicadireito.com.br/conpedi/manaus/arquivos/anais/bh/luciano soares maia.pdf. Acesso em: 21 maio 2020.

BIONI, Bruno; ZANATTA, Rafael; MONTEIRO, Renato; RIELLI, Mariana. Privacidade e pandemia: recomendações para o uso legítimo de dados no combate à COVID-19. Conciliando o combate à COVID-19 com o uso legítimo de dados pessoais e o respeito aos direitos fundamentais. São Paulo: Data Privacy Brasil, 2020. Disponível em: https://www.dataprivacybr.org/wpcontent/uploads/2020/04/relatorio privacidade e pandemia final.pdf. Acesso em: 18 maio 2020.

CNN BRASIL. O mundo pós-pandemia: Relações Pessoais. Entrevistado: Leandro Karnal. Exibição: 18 abr. 2020. Disponível em: https://www.youtube.com/watch?v=pDMAfc1ya1M. Acesso em: 19 abr. 2020.

CORONAVÍRUS: Prefeitura de Campina Grande do Sul decreta 'lockdown' em três localidades da área rural da cidade. G1; RPC Curitiba. Curitiba, 13 maio 2020. Disponível em:

https://g1.globo.com/pr/parana/noticia/2020/05/13/coronavirus-prefeitura-de-campina-grande-do-suldecreta-lockdown-em-tres-localidades-da-area-rural-da-cidade.ghtml. Acesso em: 16 maio 2020.

IBGE inicia nesta segunda pesquisa sobre evolução da Covid-19 no Brasil. Pnad Covid, como será chamado o estudo, deve ter primeira divulgação ainda em maio. Folha de São Paulo, Santos (SP), 04 de maio de 2020. Disponível em: https:/www1.folha.uol.com.br/cotidiano/2020/05/ibge-inicianesta-segunda-pesquisa-sobre-evolucao-do-covid-19-no-brasil.shtml. Acesso em: 25 maio 2020.

GONZÁLEZ, Mariana. Identidade digital na Índia: dez anos depois da implementação, o que podemos aprender com o Aadhaar? Idblog. 31 jan. 2020. Disponível em: https://blog.idwall.co/identidadedigital-na-india-dez-anos-de-aadhaar/. Acesso em: 26 maio 2020.

MARI, João de. Coronavírus: 'não somos preparados na graduação para escolher quem vai viver ou morrer', diz médico da periferia de SP. The Intercept Brasil - Vozes. 30 abri 2020. Disponível em: https://theintercept.com/2020/04/30/coronavirus-medico-brasilandia/. Acesso em: 29 maio de 2020. 
MAZZUOLI, Valerio de Oliveira. Responsabilidade internacional dos estados por epidemias e pandemias transnacionais: o caso da covid-19 provinda da República Popular da China. Revista de Direito Civil Contemporâneo | vol. 23/2020 | Abr - Jun / 2020 | DTR\2020।7115. Revista dos Tribunais online. Disponível em: https://www.revistadostribunais.com.br/maf/app/widget/document?docguid=laf7c6d2082ff11ea9e3adf 3ea497cf26. Acesso em: 21 abr. 2020.

MINISTRO da Saúde Nelson Teich pede demissão menos de um mês depois de assumir. BBC. 15 maio 2020. Disponível em: https://www.bbc.com/portuguese/brasil-52683285. Acesso em: 28 maio 2020.

OPAS/OMS Brasil. Organização Pan-Americana da Saúde/Organização Mundial da Saúde Representação no Brasil. COVID-19. Disponível em: https://www.paho.org/bra/index.php?option=com content\&view=article\&id=6101:covid19\&ltemid=875. Acesso em: 22 abr. 2020.

REGULATING the internet giants. The world's most valuable resource is no longer oil, but data. The Economist. May 5th 2017. Disponível em: https://www.economist.com/leaders/2017/05/06/the-worldsmost-valuable-resource-is-no-longer-oil-but-data. Acesso em: 18 dez. 2019.

REUTERS. Lockdown em São Luís pode ser ainda mais rígido, diz governador. Exame. 05 maio 2020. Disponível em: https://exame.abril.com.br/brasil/lockdown-em-sao-luis-pode-ser-ainda-maisrigido-diz-governador/. Acesso em 16 maio 2020.

SERPRO. O que são dados pessoais, segundo a LGPD. Disponível em: https://www.serpro.gov.br/lgpd/menu/protecao-de-dados/dados-pessoais-lgpd. Acesso em: 14 maio 2020.

SUPIOT, Alain. Homo Juridicus: ensaio sobre a função antropológica do direito. Trad. Maria Ermantina de almeida Prado Galvão. São Paulo: WMF Martins Fonte, 2007.

TAKOI, Sérgio Massaru. Breves comentários ao princípio constitucional da solidariedade. Revista dos Tribunais online. 2011 